\title{
Railways: An Acoustical Point of View
}

At the moment of writing this note, our lives have undergone such a drastic change compared to a few months ago that it is still hard to imagine going back to something similar to the previous life. If one can speak of something positive, to use a word with optimistic connotations, it is worth mentioning that restrictions associated with COVID19 lockdown have reduced acoustic emissions and corresponding noise levels of traffic in cities. In turn these reductions have allowed us to hear new sounds previously camouflaged by background noise, both those that may be pleasant and others that are not so good.

As the situation improves, it is to be expected that mobility restrictions will be removed and traffic noise will once again be a major problem that affects millions of people daily. Although the pandemic has temporarily dealt a severe blow to public transport systems in favour of other means of a private nature, global initiatives that promote the use of mass transport such as railways must continue and even be strengthened to guarantee the population safe, dependable, sustainable, intelligent and comfortable transit. Railways have the potential to operate with less pollutant emissions and energy use per passenger-km than road or air means of transportation. An earlier estimation, however, showed that about 12 million people (during the day) and 9 million people (during the night) were affected daily in the European Union by railway noise (U. Clausen et al., Reducing railway noise pollution, Policy Department B: Structural and Cohesion Policies, European Parliament, Tech. Rep., 2012). Of course, problems of a similar nature exist in megacities around the world. Urban areas seem to grow continuously and therefore a greater amount of the population is becoming affected by traffic noise exposure. Even though funding will be focused on financing coronavirus-related initiatives, it is sensible to think that research activities associated with mitigating the acoustic impact of railway traffic will be resumed with special impetus.

As suggested by Prof. David Thompson (ISVR, University of Southampton, UK), "To reduce noise effectively you first have to understand it. This is the reason we do modelling and experiments, in order to increase our understanding and hence to be better able to control noise". This understanding of the underlying phenomena in the case of railway noise and vibration encompasses extraordinarily complex mechanisms that are still an open field of research, including: wheel/track rolling noise, impact noise at discontinuities such as joints and crossings, curve squeal noise, aerodynamic noise from high-speed trains, vehicle interior noise, ground vibra- tion, ground-borne noise, etc. (D. Thompson, Railway Noise and Vibration: Mechanisms, Modelling and Means of Control, ISBN 978-0-08-045147-3, Elsevier, 2009).

In the light of the aforementioned ideas, it is therefore understandable that the European Union is making a firm commitment to the railway sector. A relevant example is the Shift2Rail Joint Undertaken (www.shift2rail.org), with both public and private investment, consisting of a partnership between the European Union and key players from the railway industry (rail equipment manufacturers, railway undertakings, infrastructure managers, and research centres). It focuses on research and innovation of rail product solutions and, amongst the impact of this initiative's results, citizens' health and well-being benefit can definitely be highlighted, due to the technological achievements related to noise and vibration pollution reduction from railway transport. Some projects directly related to noise and vibration issues in the framework of this initiative are, for example, DESTINATE (Decision supporting tools for implementation of cost-efficient railway noise abatement measures), RUN2RAIL (Innovative RUNning gear soluTiOns for new dependable, sustainable, intelligent and comfortable RAIL vehicles), FINE1 (Future Improvement for Energy and Noise) and FINE2, as well as TRANSIT (TRAin pass-by Noise Source characterIsation and separation Tools for cost-effective vehicle certification).

It must of course be borne in mind that measures aimed at reducing noise have to be compatible with safe and economic operation. These measures are especially cost-effective when applied at the source. Let us hope that all these initiatives and others like them throughout the world will come to fruition and allow the sought after social benefit. It would also be desirable, in a post-pandemic era, if they had their continuation with the same enthusiasm on the part of the people who make it possible, including researchers and technicians as well as managers.

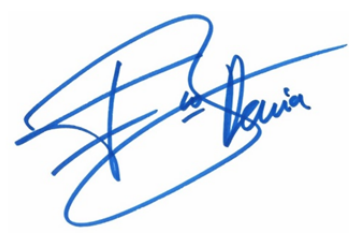

Francisco D. Denia

IJAV Associate Editor

IIAV Director 